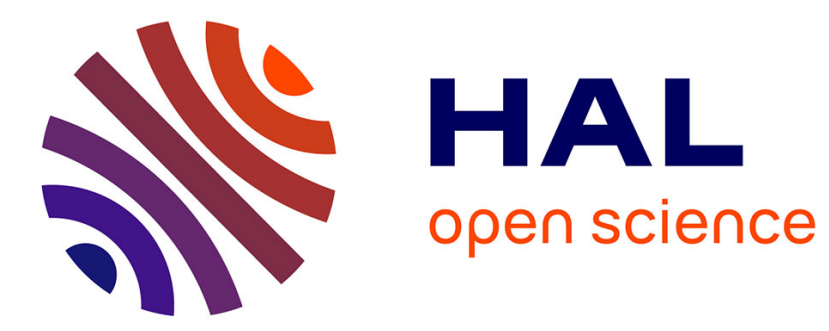

\title{
Nanolithography by high energy electron beam
}

\author{
Henri Camon, J.P. Martinez, J.L. Balladore
}

\section{To cite this version:}

Henri Camon, J.P. Martinez, J.L. Balladore. Nanolithography by high energy electron beam. Revue de Physique Appliquée, 1988, 23 (7), pp.1317-1323. 10.1051/rphysap:019880023070131700 . jpa00245947

\section{HAL Id: jpa-00245947 https://hal.science/jpa-00245947}

Submitted on 1 Jan 1988

HAL is a multi-disciplinary open access archive for the deposit and dissemination of scientific research documents, whether they are published or not. The documents may come from teaching and research institutions in France or abroad, or from public or private research centers.
L'archive ouverte pluridisciplinaire HAL, est destinée au dépôt et à la diffusion de documents scientifiques de niveau recherche, publiés ou non, émanant des établissements d'enseignement et de recherche français ou étrangers, des laboratoires publics ou privés. 
Classification

Physics Abstracts

$79.20-61.80-73.90$

\title{
Nanolithography by high energy electron beam
}

\author{
H. Camon, J. P. Martinez and J. L. Balladore \\ Laboratoire d'Optique Electronique du CNRS, lié par Convention à l'Université Paul Sabatier, 29 rue Jeanne \\ Marvig, BP 434731055 Toulouse Cedex, France
}

(Reçu le 14 janvier 1988, accepté le 12 avril 1988)

\begin{abstract}
Résumé. - L'intérêt de l'utilisation de hautes énergies $\left(E_{0}=100 \mathrm{keV}\right)$ en lithographie par électrons dans le domaine nanométrique $(<0,1 \mu \mathrm{m})$ est discuté. A partir d'un modèle de Monte Carlo, on met en évidence les contributions au dépôt d'énergie dans la résine lithographique (PMMA) des différents processus : électrons primaires, électrons rétrodiffusés et électrons secondaires. Le rôle de chacun d'eux est analysé, ainsi que son influence sur la résolution finale du tracé.
\end{abstract}

Abstract. - The theoretical advantages of high energy beam $\left(E_{0}=100 \mathrm{keV}\right)$ in electron lithography in the nanometer range $(<0.1 \mu \mathrm{m})$ are discussed. Using a Monte Carlo model, the different contributions at energy deposit in the PMMA resist are separated and the influence of each of them on the final resolution is analysed.

\section{Introduction.}

In microelectronic nanometer lithography has become a reality with the use of electron beam for drawing the circuit on a polymer resist deposited on a wafer $[1,2]$.

Progress in this domain will be done if we understand the phenomena appearing in the interactions between the incident beam and the atoms of the target (resist and wafer).

In this paper we study some aspects of this problem. We analyse the variations of the physical parameters which arise in electron beam lithography in terms of accelerating voltage of the incident electron beam.

\section{Definition of the different parameters.}

In direct writing electron lithography a monoenergetic electron beam strikes a target composed of a thin layer of polymer resist deposited on a bulk substrate (i.e. silicium or gallium arsenide). The incident particles interact with the atoms.

The etching dimensions depend essentially on two parameters :

1) the electron beam size at different depths in the resist ;

2) the energy density deposited in the polymer.

This energy is exchanged when an inelastic event occurs between the polymer atoms and : i) the incident electrons ;

ii) the electrons backscattered by the wafer ;

iii) the secondary electrons emitted when an inelastic electron-electron collision with ionization occurs in the resist.

All these phenomena can be understood if we know the elastic and inelastic interaction cross-sections between the electrons of the beam and the atoms of the target.

In the polymer the layer is very thin so the number of collisions is below 10 and we are in the domain of plural scattering. The cross-sections can be computed assuming that the target is composed of isolated atoms [3].

Let us consider a monoenergetic electron beam striking an homogeneous target. If $I_{0}$ is the incident beam intensity and $t$ the specimen thickness, the intensity transmitted through the target inside a cone of aperture angle $2 \alpha$ is given by :

$$
I(\alpha)=I_{0} \exp (-N t \sigma(\alpha))
$$

$N$ is the number of scattering atoms per unit volume. The partial scattering cross-section $\sigma(\alpha)$ outside $\alpha$ is obtained from :

$$
\sigma(\alpha)=2 \Pi \int_{\alpha}^{\Pi} Q(\theta) \sin \theta \mathrm{d} \theta
$$

where $Q(\theta)$ is the differential scattering cross-sec- 
tion per unit solid angle. In the energy ranges used $(100 \mathrm{keV})$ scattering occurs at small angles and the first Born approximation is generally valid. The Rutherford differential elastic cross-section can be employed taking into account the screening effect of atomic electrons. Assuming a Wentzel Yukawa atomic potential :

$$
V(r)=\frac{Z e}{r} \exp (-r / a) .
$$

Lenz has given a formula for $\sigma(\alpha)$ which includes inelastic scattering in the Morse approximation:

$$
\begin{aligned}
\sigma(\alpha)=\frac{\sigma_{\mathrm{e}}}{z}\left[\frac{z-1}{1+\alpha^{2} / \theta_{0}^{2}}\right. & + \\
& \left.+2 \ln \left(1+\theta_{0}^{2} / \alpha^{2}\right)\right]
\end{aligned}
$$

$\theta_{0}$ is related to the screening parameter with $\theta_{0}=1 / k a$ where $k$ is the wave vector modulus. $\sigma_{\mathrm{e}}$ is the total elastic cross-section :

$$
\sigma_{\mathrm{e}}=\frac{4 Z^{2} m^{2} e^{4} \Pi}{(h k)^{4}\left(1-\beta^{2}\right)} \cdot \frac{1}{\theta_{0}^{2}} .
$$

Equation (4) is very easy to use. However the choice of the screening parameter is crucial ; using experimental data we have computed « $a$ » for various atoms [3].

For microlithography it is essential to know the inelastic cross-section accurately. We use the Morse's approximation description of the scattering by an isolated atom. With an estimation of the incoherent scattering function given by the Raman Compton formula we obtain :

$$
\begin{aligned}
& \sigma_{\mathrm{i}}=\frac{\sigma_{\mathrm{e}}}{Z}\left[2 \ln \left(1+\theta_{0}^{2} / \theta_{E}^{2}\right)-\right. \\
& \left.\frac{1}{1+\theta_{E}^{2} / \theta_{0}^{2}}\right]
\end{aligned}
$$

$\theta_{E}$ is related to the mean energy loss $\overline{\Delta E}$ by :

$$
\theta_{E}=\gamma \overline{\Delta E} /\left(\gamma^{2}-1\right) m c^{2} .
$$

In the case of thin specimen, this expression represents satisfactorily the angular inelastic scattering by an isolated atom of electrons whose energy lies between 20 to $100 \mathrm{keV}$.

The energy lost by the incident electron when an inelastic event occurs, contributes to break or join the molecules of the resist and so locally changes its characteristics in such a way that development can either remove selectively the exposed part (positive resist) or remove the unexposed part (negative resist).

The energy deposited in the polymer is obtained with the aid of Moller's theory which is also used in order to obtain the probability of creating a secondary electron and to compute its energy [4].

In the substrate the same phenomena occur but we must consider now two points :

i) only the electrons backscattered by the wafer contribute to the lithography process.

ii) we are in this part in a bulk specimen so it it necessary to use the multiple scattering theories.

As it will be shown in the present paper the trajectory of the backscattered electron in the wafer can be simulated by taking into account only elastic scattering events outside a given angle (larger than $5 \times 10^{-3}$ radian). Partial inelastic cross-sections can be neglected in comparison with elastic scattering for elements having a high atomic number $(Z>13)$ : inelastic events correspond to very small deflection angle. However it is necessary to take into account energy lost by the incident electrons. We use the continuous slowing down Bethe approximation :

$$
\begin{gathered}
-\frac{\mathrm{d} E}{\mathrm{~d} s}=\frac{2 \Pi e^{4}}{m c^{2}} \frac{N Z}{\beta^{2}}\left[\ln \frac{(\gamma-1)\left(\gamma^{2}-1\right) m^{2} c^{4}}{I^{2}}-\right. \\
\left.-\left(1+\frac{2 \gamma-1}{\gamma^{2}}\right) \ln 2+\frac{1}{\gamma^{2}}+\frac{1}{8} \frac{(\gamma-1)^{2}}{\gamma^{2}}\right] .
\end{gathered}
$$

In the case of a wafer composed of AsGa the ponderation made on the different cross-sections of arsenic and gallium allows us to take cross-sections computed for germanium whose density is very near to that of AsGa [4].

\section{Monte Carlo method.}

Given the differential cross-sections, we can simulate electron transport in matter by a Monte Carlo method [5-7]. In the plural scattering region, experiments made on thin targets in electron microscopy allow us to compare experimental and theoretical results.

We simulate the trajectory of each electron by generating uniform pseudo-random numbers $X$. The angular deflection $\theta_{\mathrm{d}}$ of an electron that has travelled a distance $\Delta s$ through the substance is related to $X$ by :

$$
X=2 \Pi \int_{0}^{\theta_{\mathrm{d}}} F(\theta) \sin \theta \mathrm{d} \theta .
$$

During each step $\Delta s$ the angular distribution function $F(\theta)$ must be known. $\Delta s$ is short enough for us to assume that only one scattering process takes place. $F(\theta)$ is then directly connected with the differential cross-section in the single scattering model :

$$
F(\theta)=\frac{1}{\sigma} Q(\theta)
$$

and :

$$
\sigma=\int_{0}^{\Pi} Q(\theta) 2 \Pi \sin \theta \mathrm{d} \theta .
$$


We must compute the step-lengths between successive events and any energy loss suffered by the electron. We have chosen the single scattering model, which is more accurate since certain approximations are avoided. For the distribution of path lengths, we adopt a direct sampling method. Each electron undergoes a sequence of elementary events between which it advances in a straight line. The path length between the $n$-th and the $(n+1)$-th collision is related to the mean free path of the electrons in the material considered. The trajectory is divided up into elements much shorter than the mean free path. If $\Lambda_{\mathrm{e}}$ and $\Lambda_{\mathrm{i} k}$ respectively are the mean free paths for elastic scattering and for $k$-th inelastic process, the scattering probabilities on the trajectory element $\Delta L$ are respectively :

$$
\begin{aligned}
& P_{\mathrm{e}}=\frac{\Delta L}{\Lambda_{\mathrm{e}}} \\
& P_{\mathrm{i} k}=\frac{\Delta L}{\Lambda_{\mathrm{i} k}} .
\end{aligned}
$$

By associating a pseudo-random number $X$ with these different probabilities we obtain one of the events (elastic, inelastic or no interaction). Because of the symmetry of the isolated atom, the azimuth $\phi$ of the trajectory becomes a simple second random number $2 \Pi X$. Knowing the deviation $(\phi, \theta)$ resulting from the interaction we determine the direction cosines of the trajectory.

The determination of the depth $z$ reached by the electron is compared to the thickness $t$ of the sample. When $z=t$ we have :

- the angular deviation $\theta$ from the incident direction ;

- the position $(x, y)$ of the electron on the lower face and the spreading $r^{2}=\left(x^{2}+y^{2}\right)$ relative to the incident beam ;

- the electron energy, from which we can obtain the energy loss distribution.

In the case of a bulk specimen (wafer) we take into account only elastic events in order to reduce the computation time [8].

All the results presented in part 4 are obtained with the aid of this method. They correspond to the computation of 5000 electron trajectories.

\section{Results.}

4.1 PRIMARY Electrons. - When we take into account only the primary electrons the broadening of the beam in the resist at $20 \mathrm{keV}$ is six times greater than at $100 \mathrm{keV}$. This is due to two factors :

i) the scattering angles are smaller at high tension ;

ii) the number of collisions in a given thickness of material is more important at $20 \mathrm{keV}$ than at $100 \mathrm{keV}$.
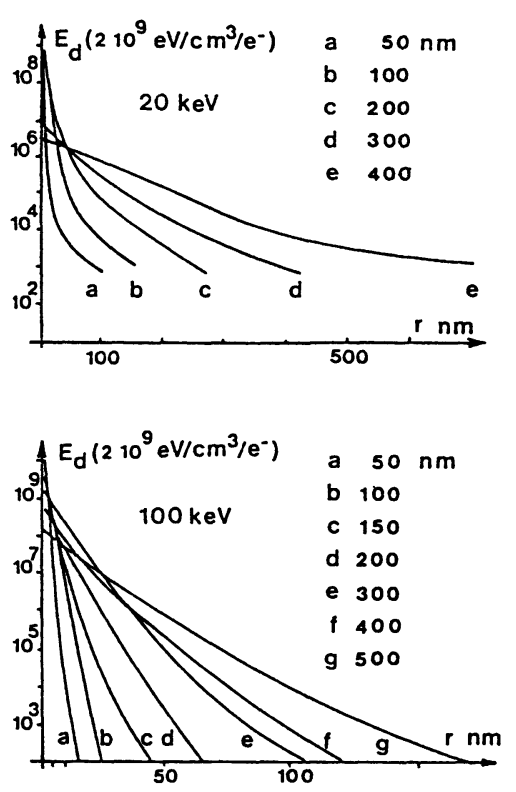

Fig. 1. - Energy densities deposited at different depths.

The energy densities deposited in the polymer at two different depths measured from the top of the resist are represented in figure 1. This energy is more concentrated near the incident beam axis at high voltage. The slopes of the curves obtained at $100 \mathrm{keV}$ are larger than at $20 \mathrm{keV}$. This point is very interesting for the development. The variations of the energy deposited being stronger, the development will be more selective and consequently the design profile more abrupt.

4.2 BACKSCATTERED ELECTRONS. - In order to study the effects due to these electrons it is necessary to have the geometrical and energetic characteristics of the backscattered beam.

We have computed, in a first step, the backscattering coefficient giving the ratio of the number of backscattered electrons on the number of incident electrons for different energies. The curves on figure 2 show that the variations of this parameter are not important for silicon. The same remark can be made for $\mathrm{AsGa}$ if we consider voltage larger than

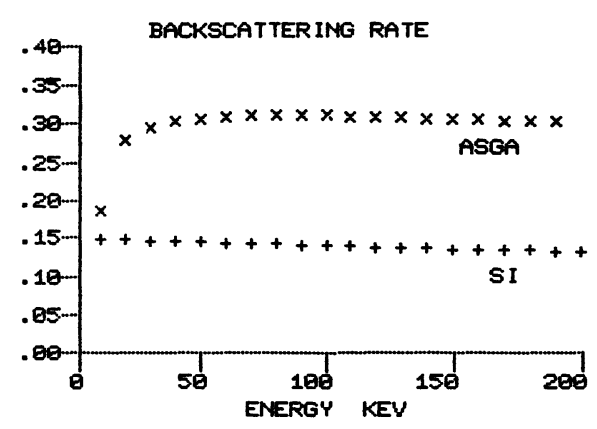

Fig. 2. - Backscattering rate. 
$20 \mathrm{kV}(0.298$ at $20 \mathrm{kV}$ for 0.314 at $100 \mathrm{kV})$. For a given incident beam striking a given target the number of backscattered electrons does not depend practically on the incident energy.

In order to follow the backscattered electrons in the resist it is necessary to know at what angle these electrons leave the wafer.

The angular distribution is shown on figure 3. These curves can be represented by a cosine law and this has been confirmed by Soum [8]. It is possible to determine the most probable angle $\theta_{\mathrm{p}}$ and the mean angle $\theta_{\mathrm{m}}$ for each distribution.

Energetic distribution has been computed for electrons whose incident energy lies between 20 and $100 \mathrm{keV}$. Figure 4 shows the results obtained. The mean energy of the backscattered electrons increases with the atomic number of the target. The normalized energy function does not depend on the incident energy $E_{0}$ : the most probable energy $E_{\mathrm{p}}$ is equal to $0.7 E_{0}$ for $\mathrm{Si}$ and to $0.82 E_{0}$ for AsGa for the two values of $E_{0}$ considered. These results are in good agreement with different values obtained theoretically an experimentally by other authors.
The spatial distribution of the mean energy of the electrons backscattered by the substract obtained in the cases of $\mathrm{Si}$ and $\mathrm{AsGa}$ are presented on figure 5.

The mean energy $E_{\mathrm{m}}(r)$ is a linear function of the distance $r$ from the incident beam axis. The curves can be described by an analytical formula :

$$
E_{\mathrm{m}}(r)=-2\left(\frac{\mathrm{d} E}{\mathrm{~d} S}\right)_{E_{0}} r+E_{0}
$$

where $(\mathrm{d} E / \mathrm{d} S)_{E 0}$ is Bethe's stopping power for an initial energy $E_{0}$. Table I shows the good agreement between the results obtained experimentally $S_{\mathrm{e}}$ and $S_{\mathrm{a}}=-2(\mathrm{~d} E / \mathrm{d} S)_{E_{0}}$.

Table I. - Comparison between experimental values of the curves slope $\left(S_{\mathrm{e}}\right)$ in $\mathrm{keV} / \mu \mathrm{m}$ and analytical values $\left(S_{\mathrm{a}}\right)$.

$$
\begin{array}{lllll} 
& \multicolumn{2}{c}{\mathrm{Si}} & \multicolumn{2}{c}{\mathrm{AsGa}} \\
& S_{\mathrm{e}} & S_{\mathrm{a}} & \multicolumn{1}{c}{S_{\mathrm{e}}} & \multicolumn{1}{c}{S_{\mathrm{a}}} \\
E_{0}=20 \mathrm{keV} & -4.7 & -4.7 & -8.85 & -8.96 \\
E_{0}=100 \mathrm{keV} & -1.4 & -1.52 & -3 & -3
\end{array}
$$
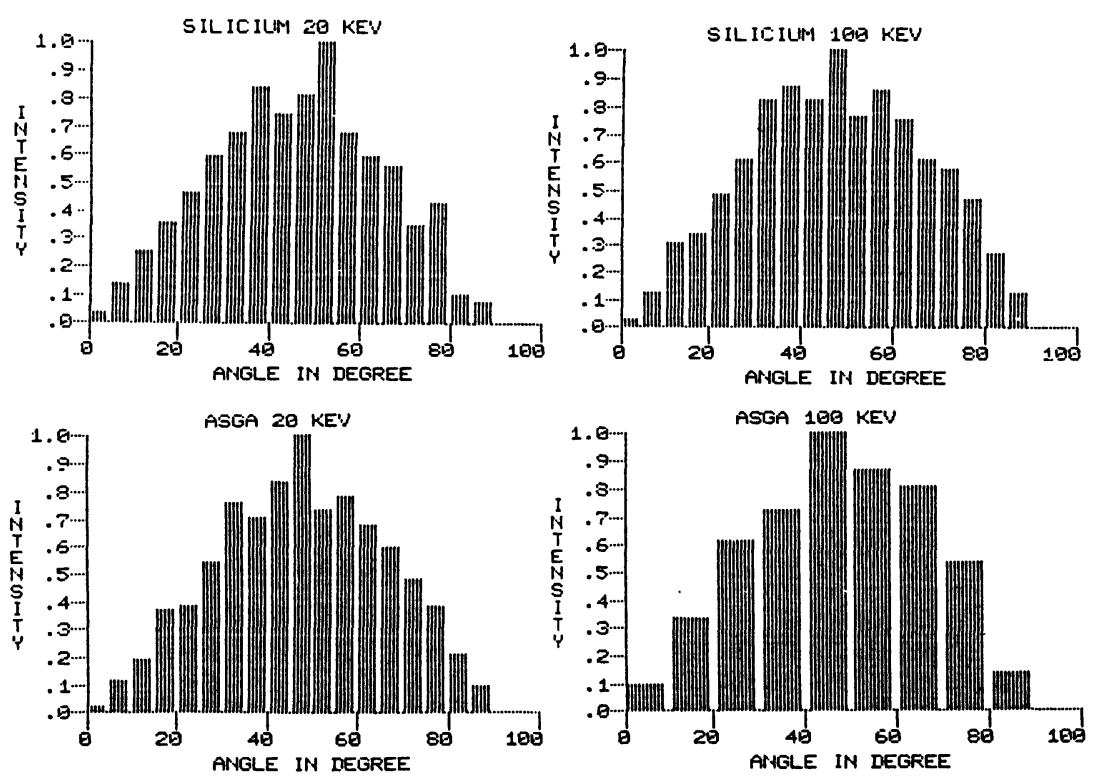

Fig. 3. - Angular distribution of backscattered electrons.
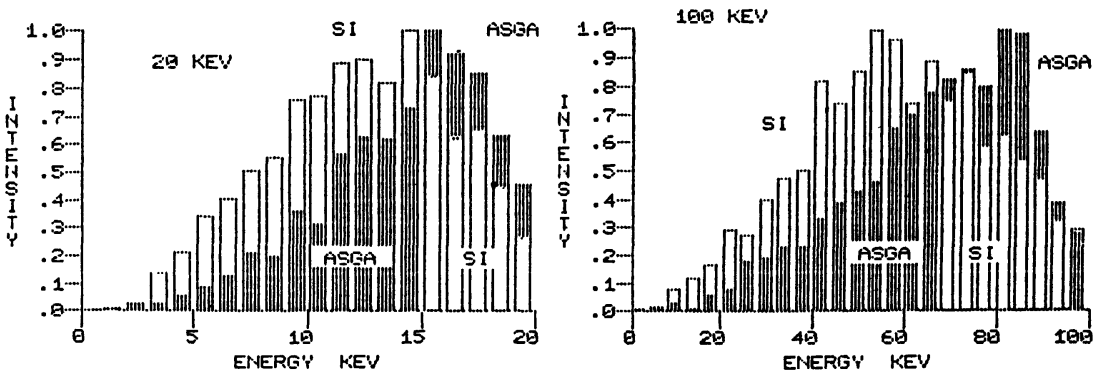

Fig. 4. - Energy distributions of backscattered electrons. 

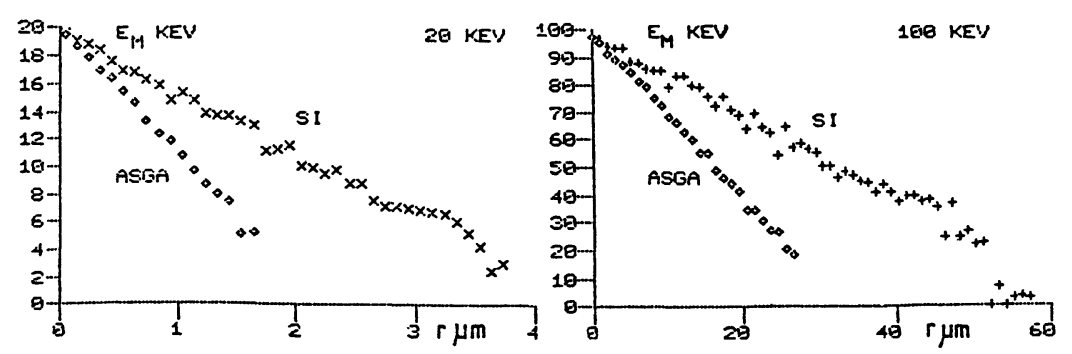

Fig. 5. - Mean energy of backscattered electrons.

With the aid of relation (14) we can compute easily the maximum radius of action of the backscattered electrons. This value is given by:

$$
r_{\mathrm{m}}=\frac{E_{0}}{2}\left[\frac{\mathrm{d} E}{\mathrm{~d} s}\right]_{E_{0}}^{-1} \text {. }
$$

Table II shows that $r_{\mathrm{m}}$ is multiplied by a factor 15 when we pass from 20 to $100 \mathrm{keV}$. The energy of the backscattered beam at $100 \mathrm{keV}$ is distributed over an area 225 times greater than at $20 \mathrm{keV}$.

Table II. - Radius of action of the backscattered electrons.

$\begin{array}{rcr} & \text { Si } & \text { AsGa } \\ & & \\ 20 \mathrm{keV} & 4.3 \mu \mathrm{m} & 2.3 \mu \mathrm{m} \\ 100 \mathrm{keV} & 70 \mu \mathrm{m} & 33 \mu \mathrm{m}\end{array}$

This point is very important. The energy backscattered is very delocalized and it is so weak that it does not contribute to resist exposure for only one line drawn on the resist. It is sure that for a more complex design it will be necessary to take into account the addition of the energies deposited as the beam writes the circuit.

An other approach of this problem is to compute the energy density at different depths measured from the top of the target as a function of the radius from the incident beam axis. The results are presented figure 6 .

Due to the important increase of the radius of the backscattered beam and to the weak variation of the backscattering coefficient, the contribution of these electrons to the lithography is very delocalized. For a $20 \mathrm{keV}$ incident beam the backscattered electrons deposit an energy whose density is a thousand time greater than at $100 \mathrm{keV}$.
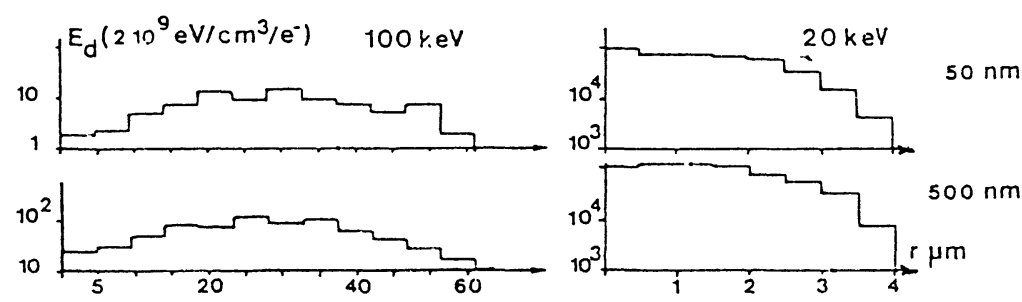

Fig. 6. - Density of energy deposited at different depths.
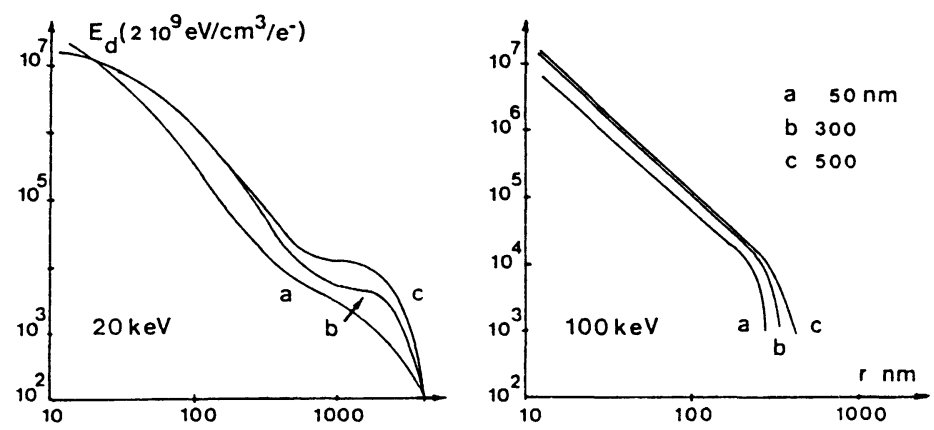

Fig. 7. - Energy deposited by secondary electrons from both primary and backscattered beams. 
4.3 SECONDARY ELECTRONS. - Secondary electrons can be produced by primary beam and by electrons backscattered from the substrate.

The contribution of the secondary electrons created by the backscattered beam is so delocalized and so weak at $100 \mathrm{kV}$ that we cannot obtain significant curves.

If we compute the energy deposition by the secondary electrons from both primary and backscattered beams we obtain the curves presented on figure 7. The influence of secondaries due to backscattered electrons appears only on curves at $20 \mathrm{kV}$ since at $100 \mathrm{kV}$ the energy deposited by secondaries is very weak.
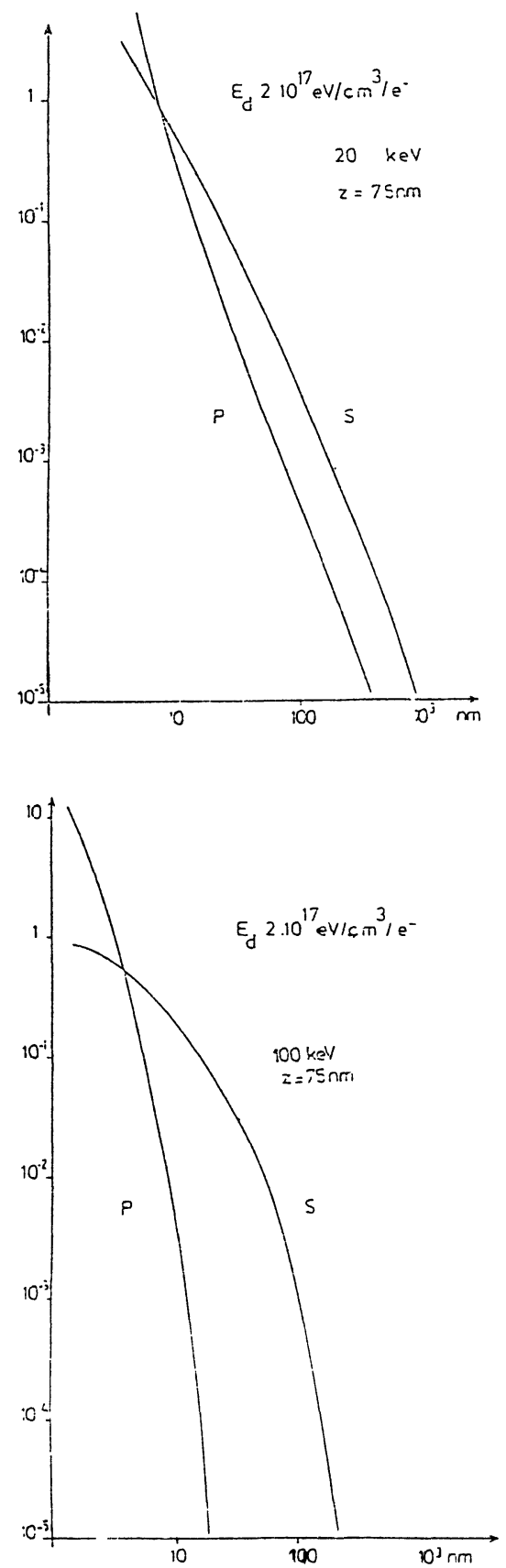

Fig. 8. - Energy deposited in the resist by primary (curves P) and secondary (curves S) electrons.
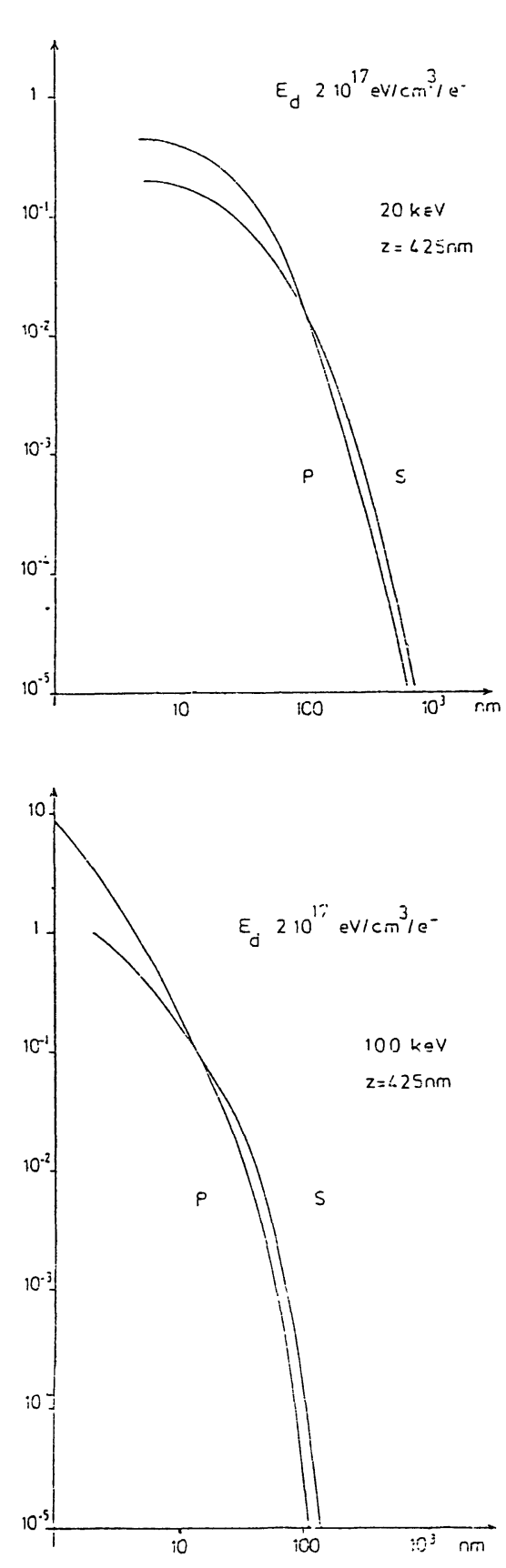

Where primary beam interacts with resist atoms secondary electrons can be produced. The contribution of these electrons to the energy deposited in the resist is presented on figure 8 , and compared to that of primary electrons.

The curves representing energy densities are drawn as a function of the distance from the incident beam axis, for two different depths measured from the top of the target, which is composed of $500 \mathrm{~nm}$ thick PMMA film on a silicon wafer.

At $20 \mathrm{keV}$, the energy deposited by secondaries is closed to that due to primaries : two processes take similar parts in the broadening of the deposit, near 

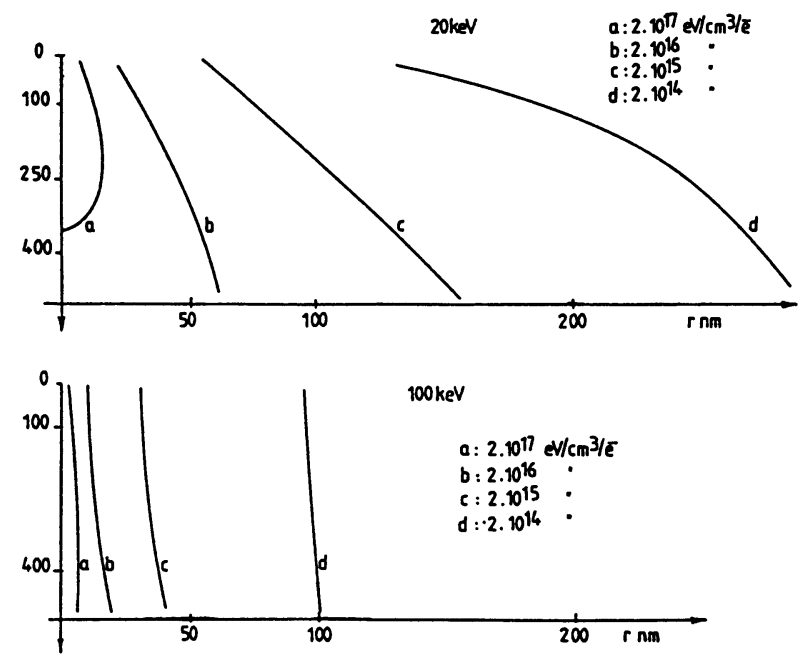

Fig. 9. - Equidensity curves for all processes together.

the surface $(z=75 \mathrm{~nm})$ as well as near the semiconductor - resist interface $(z=425 \mathrm{~nm})$.

For a $100 \mathrm{keV}$ incident beam, in opposition, secondary electrons play a leading part near the surface $(z=75 \mathrm{~nm})$, for energy densities below $10^{17} \mathrm{eV} / \mathrm{cm}^{3} / \mathrm{e}^{-}$, whereas at the interface the behaviour of the two processes is similar. In this region, the broadening of the energy deposit due to secondaries allows to obtain abrupt design profiles. If we take into account all the energy deposited by the different processes we obtain the curves presented on the figure 9. At $100 \mathrm{kV}$ near the axis the energy deposition is due to primary and corresponding secondaries electrons. The backscattered electrons effect is so weak that it can be neglected. The contribution due to the secondary electrons is more important at the top of the resist : the curves are very abrupt. The problems of proximity effects are very reduced due to the energy localization.

\section{Conclusion.}

The use of high voltage in order to obtain nanometer features by electron beam lithography presents many advantages if we consider the energy deposited by the electrons. For primary an secondary electrons this energy is concentrated near the axis. If we take into account backscattered electrons, their energetic contribution is very weak and delocalized on a very large area. This last point may be a disadvantage in the case of very dense patterns. In this case the proximity effect must be corrected for. The realisation of nanostructures used for quantum physics [9] can be easier obtained if we use high voltage electron beam lithography.

\section{References}

[1] Pfeiffer, H. C., Solid Stat. Technol. 27 (1984) 223.

[2] Massel Shearer, M., Takemura, H., Isobe, M., Goto, N., Tanaka, K. and MiYauchi, S., $J$. Vac. Sci. Technol. B 4 (1986) 64.

[3] Martinez, J. P., Balladore, J. L. and Trinquier, J., J. Ultramicroscopy 4 (1979) 211.

[4] Camon, H., Martinez, J. P. and Balladore, J. L., J. Micr. Spectrosc. Elect. 11 (1986) 1.

[5] Martinez, J. P. and Balladore, J. L., J. Micr. Spectrosc. Elect. 4 (1979) 1.
[6] Reimer, L., Optik 27 (1986) 86.

[7] Matsukawa, T., Murata, K. and Shimizu, R., Phys. Status Solidi 55 (1973) 371.

[8] Soum, G., Arnal, F., Balladore, J. L., JoufFrey, B. and VERDIER, P., Ultramicroscopy 4 (1979) 451.

[9] Bellessa, J., Carcenac, F., Izrael, A., Launois, H. and MAILlY, D., Microcircuit Engineering 87 (1987) 175. 